\title{
Building Allies and Sharing Best Practices: Cultural Perspectives of Deaf People and ASL Can Benefit All
}

Debbie Golos, Annie Moses, Elaine Gale, and Michele Berke

\begin{abstract}
Societal views of Deaf people typically stem from a medical or deficit perspective, which then informs educational practices. In contrast, educational settings that embrace a cultural perspective provide visual language and strategies that can benefit all students. This article will address three common myths about American Sign Language (ASL) and Deaf people, and share research-supported pedagogical practices and recommendations on how to be an ally on behalf of Deaf people.
\end{abstract}

\section{Building Allies and Sharing Best Practices: Cultural Perspectives of Deaf People and ASL Can Benefit All}

A greater focus on developmentally appropriate practice, including culturally responsive practices, have led educators to adapt curricula to meet the varying knowledge, beliefs, experiences, and contexts of children (e.g., NAEYC, 2020). However, misunderstandings and myths about some children's capabilities and culture persist. For example, for multilingual language learners, there has been a misunderstanding that "learning two languages during the early childhood years will overwhelm, confuse, and/or delay acquisition of English" (Espinosa, 2013, p. 5). Misunderstandings and myths apply to Deaf children's capabilities and culture as well, particularly in language learning (Humphries et al., 2012).

In this article, we first present varying perspectives on educating Deaf children. Then, we share three common myths and facts about Deaf children's language and literacy development. Finally, we present research-supported practices that educators can implement to counter these common myths and be(come) a hearing ally. This includes incorporating American Sign Language (ASL) to benefit all students, and how educators can promote positive perceptions about Deaf people in their classrooms. For the remainder of this article, we will use the term "Deaf" as an inclusive term to refer to individuals of varying hearing levels (see Table 1), diverse backgrounds, experiences, and identities (e.g., race, culture, gender).

\section{Varying Perspectives on Educating Deaf Children}

As schools embrace more inclusive environments, it is becoming common for public school teachers to have a Deaf student in their classroom (Office of Research Support and International Affairs, 2015), and those students may or may not use technologies such as cochlear implants or hearing aids. Just like all

LEARNing Landscapes | Spring 2021, Vol. 14 No. 1 | 97 
students, Deaf students often have diverse backgrounds, strengths, and needs. However, educators may not realize that they also vary in hearing level (i.e., mild to profound) and home languages (i.e., sign or spoken languages). They also vary in their language and literacy skills, with some having significant delays and others achieving grade-level (or above) expectations. A Deaf child with any of these characteristics could join a general or special education classroom, and teachers must consider how to plan and implement effective practices that will benefit Deaf learners as well as other students in their classrooms. In addition, even if they never have a Deaf student, educators can become an ally and share knowledge about Deaf culture and ASL as a part of a culturally responsive curriculum.

Practices, beliefs, and recommendations for teaching Deaf students or about Deaf people are just as varied depending on the guiding beliefs and theoretical perspectives (Humphries et al., 2012). The more typical societal views of Deaf people are from a medical or deficit perspective, which focuses primarily on their hearing; how to fix or mold them to fit into a hearing world (Lane et al., 1996). Decisions about their education are often informed, in turn, by this perspective. For instance, recommendations typically stem from best practices for hearing children, such as developing spoken language and/or learning literacy through sound-based approaches (e.g., Wang et al., 2008; Fitzpatrick et al., 2016). In fact, sign language is not used with the majority of Deaf children (Office of Research Support and International Affairs, 2015). Despite being a popular practice with very young hearing children (baby sign), some still argue that sign language can delay spoken language development (e.g., Geers et al., 2017).

In contrast, educators aligning with a cultural perspective do not view being Deaf as a deficit; rather, they value Deaf Culture and recognize how Deaf people contribute to society. This concept is known as Deaf Gain (Bauman \& Murray, 2014), and it recognizes Deaf individuals as visual beings with their own language and culture, including a rich history of art, theater, sports, and language (ASL in the United States; see Table 1 for this and other related terms). From this perspective, researchers and theorists suggest that a visual language, like ASL, and visual strategies, benefit all children. These are the same strategies and language Deaf adults use with their own Deaf child(ren) and/or students in the classroom, helping children make connections between ASL and English (e.g., Moses et al., 2018). Researchers also recommend access to Deaf peers and Deaf adult role models, including Deaf professionals, from the early years and on (Gale, 2020; Moses et al., 2018; Cawthon et al., 2016). Children with a range of hearing levels, including hearing children, can learn from interactions with culturally and linguistically diverse role models (Cawthon et al., 2016; García-Fernández, 2014). 
Table 1

Terms commonly used by the Deaf Community (adapted from NAD, n.d.)

\begin{tabular}{|l|l|}
\hline ASL & $\begin{array}{l}\text { American Sign Language is used by the Deaf community in the United States and parts of } \\
\text { Canada. (Other countries have their own sign language(s).) }\end{array}$ \\
\hline Deaf & $\begin{array}{l}\text { Capital "D" refers to members of the Deaf community who use sign language (e.g., ASL, } \\
\text { Black ASL) as their preferred language of choice; including people with multiple } \\
\text { identities and varying hearing levels who identify as part of the Deaf community. While } \\
\text { "person first" language is acceptable, it is also acceptable to call someone "Deaf." This } \\
\text { term is sometimes used as an all-encompassing term to include Deaf, deaf, Hard of } \\
\text { Hearing, DeafBlind and DeafDisabled populations. }\end{array}$ \\
\hline $\begin{array}{l}\text { Hard of } \\
\text { Hearing }\end{array}$ & $\begin{array}{l}\text { A person with a mild-to-moderate level of hearing who identifies as hard of hearing and } \\
\text { may or may not choose to have cultural affiliation with the Deaf community. }\end{array}$ \\
\hline deaf & Lowercase "d" deaf used to define a medical condition designating the inability to hear. \\
\hline Hearing & $\begin{array}{l}\text { A person recognized as a member of the hearing community at large, someone who } \\
\text { typically is able to hear. }\end{array}$ \\
\hline Hearing level & $\begin{array}{l}\text { The cultural description of what level someone can hear, contrasts the medical term } \\
\text { "hearing loss," which is perceived as a negative term (profound level of hearing vs a } \\
\text { profound hearing loss). }\end{array}$ \\
\hline $\begin{array}{l}\text { Inappropriate } \\
\text { terms }\end{array}$ & $\begin{array}{l}\text { The terms "hearing impaired," "deaf-mute," and "deaf and dumb" are not acceptable } \\
\text { terms to describe someone who is deaf or hard of hearing. }\end{array}$ \\
\hline
\end{tabular}

However, a recent survey of educators of both hearing and Deaf children revealed that such linguistic and cultural models are not usually incorporated into educational settings, such as early childhood programs (Golos et al., 2018). This may be due to educators focusing more on sound-based approaches to learning (Fitzpatrick et al., 2016). These are missed opportunities to build upon Deaf children's visual strengths and connect to cultural needs. Teachers with or without Deaf students can invite Deaf adults into the classroom, incorporate ASL, and use visual strategies to benefit all students. Before implementing these practices, teachers should first consider what research shows and clarify misconceptions about Deaf individuals' learning and development.

\section{Myths and Facts: Language and Literacy Development in Deaf Children}

Although signing with hearing babies is quite popular, myths persist about the importance of sign language for Deaf children. Here are three prominent myths related to Deaf people, ASL, and language and literacy development as well as evidence to counter them.

\section{Myth 1: If Deaf Children Learn Sign Language, They Will Not Learn How to Speak Well}

There is a long-standing debate in Deaf education about the value of sign language that dates back to the late 1800s (Burke, 2018; Traynor, 2016). More recently, Roberta Cordano, J.D. (2016), the current president of Gallaudet University - the world's first and only liberal arts university for Deaf studentsaddressed this myth. She pointed to the research showing that learning sign language does not negatively affect language or academic skills, including spoken language development (e.g., Allen et al., 2014; 
Mayberry et al., 2011). On the contrary, early exposure to ASL encourages Deaf children, including those with cochlear implants, to excel in many domains (Dammeyer, 2014; Davidson et al., 2014). Even hearing children's language and literacy skills can improve from learning sign language (Moses et al., 2015; Brereton, 2008; Daniels, 2004).

Yet, sign language continues to be undervalued. There is a critical period for language acquisition (Penicaud et al., 2013; Petitto, 2009), and children who are exposed to a fully accessible language from birth can develop both first and second languages on an expected timeline (Skotara et al., 2012). For Deaf children, a fully accessible language is usually a visual one, such as ASL. Without it, children may experience severe delays socially, linguistically, and academically (Huber \& Kipman, 2011; Mayberry, et al., 2011). Many families, however, are advised to focus on spoken-language development only and that their children can learn sign language later if they are unsuccessful with spoken language (Geers et al., 2017; Fitzpatrick et al., 2016).

If, however, families and teachers wait to see if the Deaf child will succeed with spoken language before exposing them to ASL, the child may miss the critical window for language acquisition (Allen et al., 2014; Petitto, 2009). Speech may never be accessible for some Deaf children. Even Deaf children with cochlear implants may not have complete access to spoken language and may not be able to function independently without support (Punch \& Hyde, 2011; Schafer \& Cokely, 2016). Without the foundation of a fully accessible language, they may experience "language deprivation" (Glickman \& Hall, 2018; Gulati, 2019; Hall et al., 2017). Early exposure to ASL can help mitigate the impact of language deprivation, and there is no harm in doing so (Lange et al., 2013). Teachers should not hesitate to incorporate ASL into the classroom (Hall et al., 2019).

\section{Myth 2: The Definition of Sign Language Includes All Manual Communication Systems}

Often, people use the term "sign language" to encompass both natural sign languages, such as ASL, and manual communication systems (e.g., Signed English) (Fitzpatrick et al., 2016; Geers et al., 2017). However, there is a significant difference. ASL is a natural language with its own syntax and grammar that is distinct from spoken English and is based on principles of visual communication (Perlmutter, 2001). When people talk and sign at the same time or use signing that follows the structure of English word order, they are not modeling a language but manual representations of spoken English. These systems or modes have little meaning to students unfamiliar with spoken English, and they do not receive a complete message in either ASL or English when these systems are used (Tevenal \& Villanueva, 2009). Yet, using ASL (rather than manual communication) can increase student learning and engagement (Schick \& Gale, 1995). As Hall et al. (2019) describe, "We are not aware of anyone who would argue that such communication systems confer the same benefits of a natural sign language" (p. 270).

Hall and colleagues (2019) also write that claims made in studies like Geers and colleagues (e.g., 2011; 2017) and Fitzpatrick and colleagues (2016) should be read with caution. For example, researchers collapsed all forms of sign into one definition when assessing participants' language use. This does not accurately portray their authentic exposure to sign language nor their sign language use and/or abilities. 
Building Allies and Sharing Best Practices: Cultural Perspectives of Deaf People and ASL Can Benefit All

Furthermore, unless evaluators are knowledgeable of ASL structure, they cannot accurately assess or make data-informed decisions about children's sign language or other academic skills (Simms et al., 2013).

\section{Myth 3: Deaf Children's Language and Literacy Skills Will Be Delayed if They Do Not Have Access to Spoken Language}

There is a long history of Deaf children graduating from high school with severe delays in literacy skills (Mitchell \& Karchmer, 2004). Some have attributed this to the lack of access to spoken language (e.g., Geers et al., 2017). This helps to explain why current practice for Deaf children most often relies on one route to literacy, through spoken language (i.e., listening and speaking) connected to print. More often than not, the push is to use sound-based approaches for teaching literacy (Wang et al., 2008).

An alternative explanation for delayed literacy skills relates to language deprivation, as described earlier. In fact, when Deaf children are exposed to ASL from birth, they can develop critical early literacy skills prior to conventional reading and continue to develop literacy skills on or above grade level (Caselli et al., 2021; Hrastinski \& Wilbur, 2016; Scott \& Hoffmeister, 2017). Deaf children with cochlear implants who had higher ASL skills also had higher language and literacy skills, compared with children with cochlear implants who had little to no ASL skills (Allen, 2015; Dammeyer, 2014; Davidson et al., 2014).

Thus, adults should not wait to engage with ASL and print with Deaf children, even if they are just beginning to learn to sign. They can use strategies to help Deaf or hearing children make connections between ASL and spoken or written language (Lange et al., 2013). They also can utilize supplementary methods (e.g., gesture, acting out stories) and materials (e.g., literacy-related apps or DVDs in ASL; see Appendix) to expose children to different types of text while they are learning to sign (Snoddon, 2015).

\section{Countering Myths by Be(com)ing a Hearing Ally}

Research in Deaf education offers suggestions for strategies and activities that align with a cultural perspective and the guiding principles of hearing allyship (http://www.hearingallyship.org/). Much like considering other aspects of identity such as race, ethnicity, and gender, any educator can be an ally for Deaf people and foster future allies in their students (e.g., Brown \& Ostrove, 2013), especially those who interact with Deaf students in inclusive settings. The following suggestions are evidence-based practices educators can use to integrate ASL and visual strategies into classrooms for all students and also foster understanding and positive perceptions about Deaf people (Bauman \& Murray, 2014; Cawthon et al., 2016; Freel et al., 2011; García-Fernández, 2014; Holcomb, 2013).

\section{Incorporating ASL and Visual Strategies Benefits All Students}

As already highlighted, all students, including Deaf students with cochlear implants and hearing students (Most et al., 2009), can benefit from visual supports to access the world around them. For example, they may use alternative pathways to literacy such as ASL instead of, or in addition to sound, to access English print (McQuarrie \& Abbott, 2013; Mayberry et al., 2011). In fact, researchers have found increased scores 
in children's vocabulary and reading when teachers incorporated ASL into literacy instruction with hearing children either live (e.g., Brereton, 2008; Daniels, 2004) or through media (Moses et al., 2015). These findings suggest that using a visual language like ASL can uniquely support all children, including those who struggle with sound-based approaches or cannot access sound.

Thus, all teachers may enhance student learning by incorporating ASL and visual strategies. Teachers do not have to be fluent in ASL to begin to incorporate effective strategies into homes or classrooms. The following examples are drawn from research on Deaf adults' engagement with Deaf children at home (Berke, 2013) and school (Stone et al., 2015; Allen, 2015; Allen et al., 2014; Ramsey \& Padden, 1998), reinforcing that all students can benefit from using ASL and the following strategies:

- Incorporate ASL in the classroom. For example, if a teacher has a word wall, they can show the ASL sign and/or fingerspelled word with English print (along with print in other languages; see Fig. 1). This also models respect for and equity for both languages while providing visual learners with additional support for word learning.

- Wait for the student. Deaf students and visual learners may need to attend to a book or other object and then look at the adult either before or afterward. This sequential (rather than simultaneous) joint attention allows children to explore and make connections between the language and the object.

- Use chaining or sandwiching. Each strategy is particularly effective to target vocabulary when reading books with students. Adults define the word, point to a written word, sign the word, fingerspell the word, and then show the printed word again (i.e., chaining; see Figure 2) or sign the word, define the word, fingerspell the word, and sign the word (i.e., sandwiching). Teachers can use multiple combinations of these strategies as they are defining new words.

- Encourage shared reading opportunities. Shared reading is associated with positive literacy outcomes. Adding ASL can only increase the benefit for all students by providing multiple routes to literacy (see Appendix for stories in ASL). While it is important for all students to have exposure to books, for Deaf students, it is especially important to have access to shared reading in ASL (see Figure 3).

If educators do have a Deaf student in their classroom, in addition to the above, consider the following:

- Provide access to fluent models of ASL and equal access to communication and education (e.g., closed captioning on all media materials).

- Have and effectively utilize an ASL interpreter. Encourage the school to ensure that the interpreter is highly qualified and certified. Interact directly with Deaf students even in the presence of an interpreter. (For more information about working with an interpreter, see Moses et al., 2018).

- Acknowledge that Deaf students need time to read or view visual information (e.g., on a screen or board) before shifting their gaze back to the teacher/interpreter. Also consider that there might be a time delay between the teacher's spoken word and the interpreter's interpretation. 


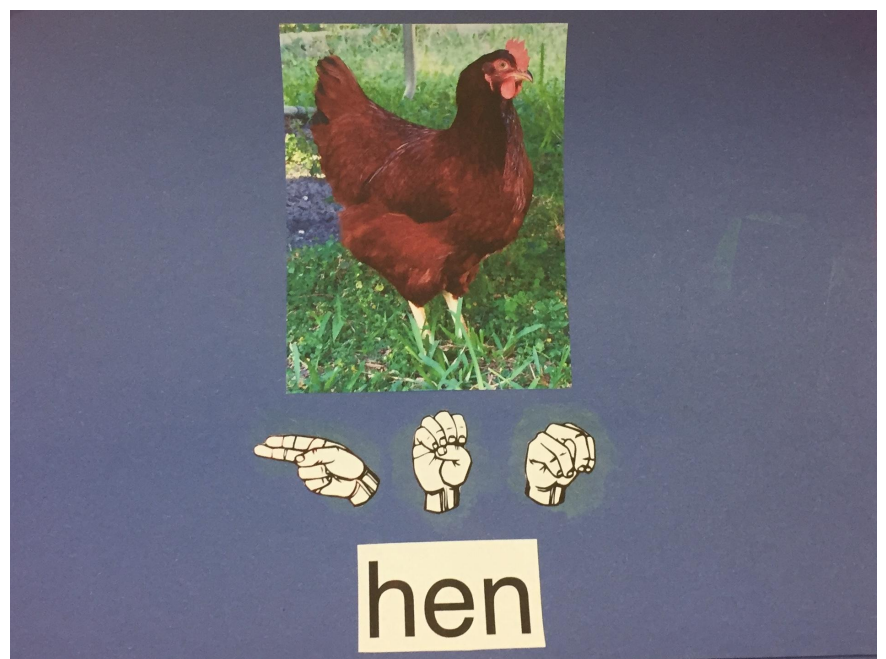

Fig. 1: This is an example of a vocabulary word displayed in picture, English print, and fingerspelling.

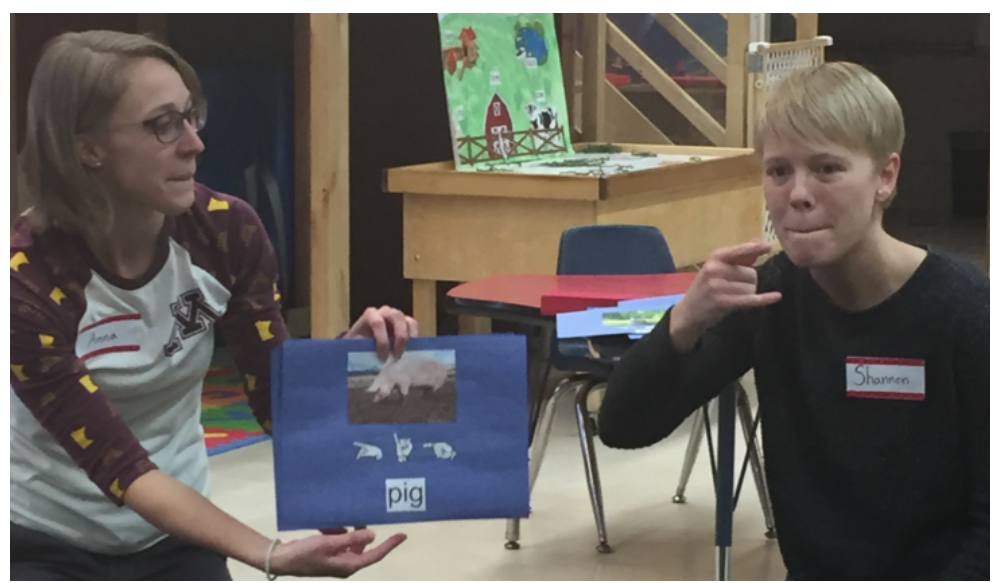

Fig. 2: Graduate students modeling chaining with preschool children (Captured here is the process of transitioning between fingerspelling the letter " $\mathrm{i}$ " and " $\mathrm{g}$ " after pointing to the printed word and signing "pig").

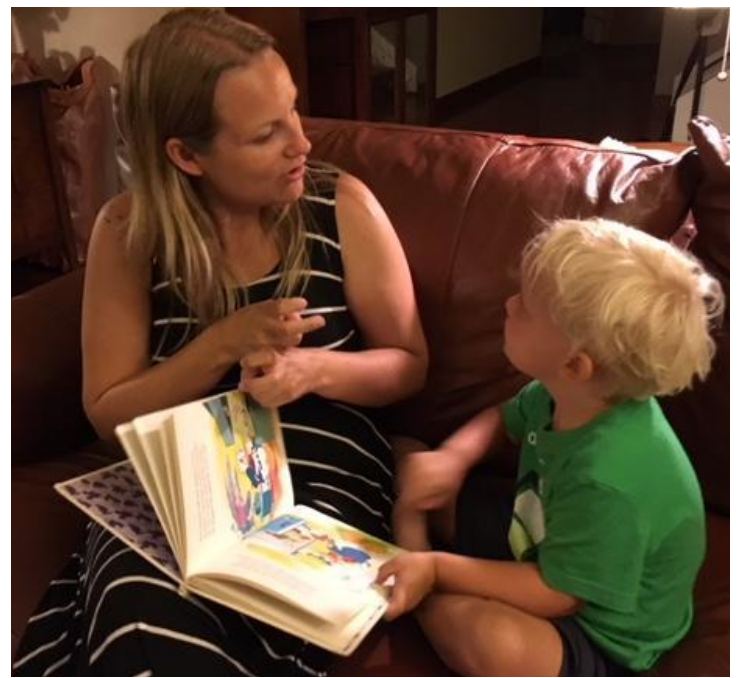

Fig. 3: A Deaf adult and Deaf child share a book together in ASL. 


\section{Promoting Positive Perceptions About Deaf People}

Perceptions of others and one's own identity develop quite early in life. These perceptions are constantly being molded throughout their schooling. Therefore, the experiences children have influence how they come to perceive themselves, others, and the world around them (Cawthon et al, 2016; Derman-Sparks \& Edwards, 2010; Leigh, 2009; García-Fernández, 2014). For educators and families, it is never too early to start building self-awareness or future allies to Deaf people, and these practices should continue throughout schooling. Yet, cultural perspectives of Deaf people are rarely included within the curriculum for Deaf or hearing children. To do this, consider the following:

- Have high expectations. Understand Deaf students (and some hearing students) as "visual learners" with multiple intersecting identities (e.g., race, gender, culture, hearing level) and showcase all that Deaf people can achieve.

- Encourage others (i.e., educators, students, families, administrators) to learn ASL (see Appendix for free resources).

- Provide opportunities for interactions with Deaf and hearing peers. Social interactions are equally as important as interacting in academic language.

- Reach out to members of the Deaf community with diverse backgrounds (i.e., race, gender, culture, hearing level, languages). Invite them into the classroom, to share their experiences living as a Deaf individual, and best educational practices. For example, they can sign stories in ASL as well as suggest ways to improve lighting, seating, and space for visual learners.

- Incorporate both informational resources and stories, such as books and media in ASL with Deaf people/characters, that portray positive messages about Deaf people from varying backgrounds throughout the curriculum and environment (e.g., Moses et al., 2018; See Appendix). Make sure to "call out" that they are Deaf.

- Review materials ahead of time and consider the messages conveyed as many books/media do not portray Deaf people from a cultural perspective (see Moses et al., 2018, for a review of books and media with Deaf characters)

- Help educators, administrators, and particularly families with Deaf children find accurate information about language, literacy, and identity development. Assist them in connecting with people and resources from the Deaf community.

Teachers also can provide ongoing interactions with Deaf adults and Deaf peers from diverse race, gender, and cultural backgrounds (Bat-Chava, 2010; García-Fernández, 2014).

\section{Conclusion}

Educators can shift from a deficit viewpoint to a cultural perspective by focusing on what Deaf people can do rather than what they physically cannot do. Regardless of whether educators ever have Deaf students in their classroom, all students can benefit from learning about ASL and Deaf people from a cultural perspective. Educators and families can align with a cultural perspective by valuing who Deaf people are as visual beings, including their cultures (i.e., Deaf and additional family cultures) and 
Building Allies and Sharing Best Practices: Cultural Perspectives of Deaf People and ASL Can Benefit All

languages (i.e., ASL, English and other spoken, written or signed languages in the home) (Bauman \& Murray, 2014). Then, their strategies, activities, and materials may be used to build upon a Deaf student's assets by way of visual strategies. Deaf adults given this foundation learn the various ways of "being" Deaf in a hearing environment and pass down these culturally based solutions for effective living (Holcomb, 2013).

With exposure to diverse Deaf role models, ASL, and visual strategies, Deaf and hearing students' language and literacy skills can improve (Allen et al., 2014; Cawthon et al., 2016; Freel et al., 2011). In addition, Deaf students may grow to embrace their strengths and develop a stronger sense of self-worth (Cawthon et al., 2016). Hearing students may grow to have a deeper understanding of the Deaf cultural perspective, value Deaf people as visual beings and, eventually, become allies.

\section{Note}

1. We recognize there may be more than one definition of Hard of Hearing. As such, children might be labeled hard of hearing based on hearing level rather than their preferred identity.

\section{References}

Allen, T. E. (2015). ASL skills, fingerspelling ability, home communication context and early alphabetic knowledge of preschool-aged deaf children. Sign Language Studies, 15(3), 233-265. https://doi:10.1353/sls.2015.0006

Allen, T. E., Letteri, A., Choi, S. H., \& Dang, D. (2014). Early visual language exposure and emergent literacy in preschool deaf children: Findings from a national longitudinal study. American Annals of the Deaf, 159(4), 346-358. https://doi:10.1353/aad.2014.0030

Bat-Chava, Y. (2000). Diversity of deaf identities. American Annals of the Deaf, 145, 420-428. https://doi:10.1353/aad.2012.0176

Bauman, H-D., \& Murray, J. J. (2014). Deaf gain: Raising the stakes for human diversity. Minneapolis: University of Minnesota Press.

Berke, M. (2013). Reading books with young deaf children: Strategies for mediating between American Sign Language and English. The Journal of Deaf Studies and Deaf Education, 18(3), 299-311. https://doi.org/10.1093/deafed/ent001

Brereton, A. (2008). Sign language use and the appreciation of diversity in hearing classrooms. Early Years: An International Journal of Research and Development, 28(3), 311-324. https://doi:10.1080/09575140802393702

Brown, K. T., \& Ostrove, J. M. (2013). What does it mean to be an ally?: The perception of allies from the perspective of people of color. Journal of Applied Social Psychology, 43(11), 2211-2222. https://doi:10.1111/jasp.12172

Burke, J. (2018, May). The Milan conference of 1880: When sign language was almost destroyed. Verywell Health. https://www.verywellhealth.com/deaf-history-milan-1880-1046547 
Debbie Golos, Annie Moses, Elaine Gale, and Michele Berke

Caselli, N., Pyers, J., \& Lieberman, A. M. (2021). Deaf children of hearing parents have age-level vocabulary growth when exposed to ASL by six months. The Journal of Pediatrics.

Cawthon, S. W., Johnson, P. M., Garberoglio, C. L., \& Schoffstall, S. J. (2016). Role models as facilitators of social capital for Deaf individuals: A research synthesis. American Annals of the Deaf, 161(2), 115-127. https://www.jstor.org/stable/26235257

Cordano, R. (2016, April 6). Gallaudet's President Cordano dispels the myths of language acquisition. Gallaudet University News. https://www.gallaudet.edu/news/president-cordano-statement

Dammeyer, J. (2014). Literacy skills among deaf and hard of hearing students and students with cochlear implants in bilingual/bicultural education. Deafness \& Education International, 16, 108-119. https://doi:10.1179/1557069X13Y.0000000030

Daniels, M. (2004). Happy hands: The effect of ASL on hearing children's literacy. Literacy Research and Instruction, 44(1), 86-100. https://doi:10.1080/19388070409558422

Davidson, K., Lillo-Martin, D., \& Chen Pinchler, D. (2014). Spoken English language development among native signing children with cochlear implants. The Journal of Deaf Studies and Deaf Education, 19(2), 238-250. https://doi:10.1179/1557069X13Y.0000000030

Derman-Sparks, L., \& Edwards, J. O. (2010). Anti-bias education for young children and ourselves. Washington, DC: National Association for the Education of Young Children.

Espinosa, L. (2013). Pre-K-3rd: Challenging common myths about dual language learners. Foundation for Child Development. https://www.fcd-us.org/prek-3rd-challenging-common-myths-about-duallanguage-learners-an-update-to-the-seminal-2008-report/

Fitzpatrick, E. M., Hamel, C., Stevens, A., Pratt, M., Moher, D., Doucet, S. P., Neuss, D., Bernstein, A., \& Na. E. (2016). Sign language and spoken language for children with hearing loss: A systematic review. Pediatrics, 137(1). https://pediatrics.aappublications.org/content/137/1/e20151974

Freel, B. L., Clark, M. D., Anderson, M. L., Gilbert, G., Musyoka, M. M., \& Hauser, P. C. (2011). Deaf individuals' bilingual abilities: American Sign Language proficiency, reading skills, and family characteristics. Psychology, 2, 18-23. https://doi:10.1093/deafed/env072

Gale, E. (2020). Collaborating with deaf adults in early intervention. Young Exceptional Children, https://doi:1096250620939510

García-Fernández, C. (2014). Deaf-Latina/Latino critical theory in education: The lived experiences and multiple intersecting identities of Deaf-Latina/o high school students (Unpublished doctoral dissertation). The University of Texas at Austin.

Geers, A. E., Carson, C. M., Warner-Czyz, A., Wang, N-Y., Eisenberg, L. S., \& the CDaCl Investigative Team. (2017). Early sign language exposure and cochlear implant benefits. Pediatrics, 140(1). https://pediatrics.aappublications.org/content/140/1/e20163489

Geers, A. E., \& Sedey, A. L. (2011). Language and verbal reasoning skills in adolescents with 10 or more years of cochlear implant experience. Ear and Hearing, 32(1 Suppl), 39S-48S.

https://doi:10.1097/AUD.0b013e3181fa41dc

Glickman, N. S., \& Hall, W. C. (Eds.). (2018). Language deprivation and deaf mental health. Routledge. 
Building Allies and Sharing Best Practices: Cultural Perspectives of Deaf People and ASL Can Benefit All

Golos, D., Moses, A., Roemen, B., \& Cregan, G. (2018). Cultural and linguistic role models: A survey of early childhood educators of the deaf. Sign Language Studies, 19(1), 40-74.

Gulati, S. (2019). Language deprivation syndrome. In N. S. Glickman \& W. C. Hall (Eds.), Language deprivation and Deaf mental health (pp. 24-53). Routledge.

Hall, M. L., Hall, W. C., \& Caselli, N. K. (2019). Deaf children need language, not (just) speech. First Language, 39(4), 367-395. https://doi:10.1177/0142723719834102

Hall, W. C., Levin, L. L., \& Anderson, M. L. (2017). Language deprivation syndrome: A possible neurodevelopmental disorder with sociocultural origins. Social Psychiatry and Psychiatric Epidemiology, 52, 761-776. https://doi:10.1007/s00127-017-1351-7

Holcomb, T. (2013). Introduction to American Deaf culture. Oxford University Press.

Hrastinski, I., \& Wilbur, R. B. (2016). Academic achievement of Deaf and hard-of-hearing students in an ASL/English bilingual program. The Journal of Deaf Studies and Deaf Education, 21(2),156-170. https://doi:10.1093/deafed/env072

Huber, M., \& Kipman, U. (2011). The mental health of deaf adolescents with cochlear implants compared to their hearing peers. International Journal of Audiology, 50(3), 146-154.

https://doi:10.3109/14992027.2010.533704

Humphries, T., Kushalnagar, P., Mathur, G., Napoli, D. J., Padden, C., Rathmann, C., \& Smith, S. R. (2012). Language acquisition for deaf children: Reducing the harms of zero tolerance to the use of alternative approaches. Harm Reduction Journal, 9(1), 2-9. https://doi:10.1186/1477-7517-9-16

Lane, H., Hoffmeister, R., \& Bahan, B. J. (1996). A journey into the Deaf-world. DawnSignPress.

Lange, C. M., Lane-Outlaw, S., Lange, W. E., \& Sherwood, D. L. (2013). American Sign Language/ English bilingual model: A longitudinal study of academic growth. The Journal of Deaf Studies and Deaf Education, 18, 532-544. https://doi:10.1093/deafed/ent027

Leigh, I. W. (2009). Perspectives on deafness. A lens on deaf identities. Oxford University Press.

Mayberry, R. I., Chen, J. K., Witcher, P., \& Klein, D. (2011). Age of acquisition effects on the functional organization of language in the adult brain. Brain and Language, 119(1), 16-29.

https://doi:10.1016/j.bandl.2011.05.007

Mayberry, R. I., Del Giudice, A. A., \& Lieberman, A. M. (2011). Reading achievement in relation to phonological coding and awareness in Deaf readers: A meta-analysis. The Journal of Deaf Studies and Deaf Education, 16(2), 164-188. https://doi:10.1093/deafed/enq049

McQuarrie, L., \& Abbott, M. (2013). Bilingual deaf students' phonological awareness in ASL and reading skills in English. Sign Language Studies, 14(1), 80-100. https://doi:10.1353/sls.2013.0028

Mitchell, R. E., \& Karchmer, M. A. (2004). Chasing the mythical ten percent: Parental hearing status of Deaf and Hard of Hearing students in the United States. Sign Language Studies, 4(2), 138-163. https://doi:10.1353/sls.2004.0005

Moses, A. M., Golos, D. B., \& Bennett, C. M. (2015). An alternative approach to early literacy: The effects of ASL in educational media on literacy skills acquisition for hearing children. Early Childhood Education Journal. Advanced online publication. https://doi:10.1007/s10643-015-0690-9 
Moses, A. M., Golos, D. B., \& Holcomb, L. (2018). Perspectives on Practice: Creating and using educational media with a cultural perspective of Deaf people. Language Arts, 96(1), 67-71.

Most, T., Rothem, J., \& Luntz, M. (2009). Auditory, visual, and auditory-visual speech perception by individuals with cochlear implants versus individuals with hearing aids. American Annals of the Deaf, 154(3), 284-292. https://doi:10.1353/aad.0.0098

National Association for the Deaf. (N.d.). Community and culture-frequently asked questions. https://www.nad.org/resources/american-sign-language/community-and-culture-frequently-askedquestions/

National Association for the Education of Young Children (NAEYC). (2020). Developmentally appropriate practice. Position statement. Washington, DC: National Association for the Education of Young Children.

Office of Research Support and International Affairs. (2015). Gallaudet University's annual survey of Deaf and hard of hearing children \& youth. https://www.gallaudet.edu/research-support-andinternational-affairs/research-support/research-resources/demographics

Penicaud, S., Klein, D., Zatorre, R. J., Chen, J. K., Witcher, P., Hyde, K., \& Mayberry, R. I. (2013). Structural brain changes linked to delayed first language acquisition in congenitally deaf individuals. Neurolmage, 66, 42-49. https://doi:10.1016/j.neuroimage.2012.09.076

Perlmutter, D. L. (2001). Resolution: Sign language. https://www.linguisticsociety.org/resource/resolution-signlanguages

Petitto, L. A. (2009). New discoveries from the bilingual brain and mind across the lifespan: Implications for education. Mind, Brain, and Education, 3(4), 185-197.

Punch, R., \& Hyde, M. (2011). Communication, psychosocial, and emotional outcomes of children with cochlear implants and challenges remaining for professionals and parents. International Journal of Otolaryngology, 2011. https://www.hindawi.com/journals/ijoto/2011/573280/

Ramsey, C., \& Padden, C. (1998). Natives and newcomers: Gaining access to literacy in a classroom for deaf children. Anthropology \& Education Quarterly, 29(1), 5-24. www.jstor.org/stable/3196099

Schafer, G., \& Cokely, D. (2016). Report on the national needs assessment initiative: New challenges - needed changes. http://www.interpretereducation.org/wp-content/uploads/2016/03/NA_Legacy Report 3 2016.pdf

Schick, B., \& Gale, E. (1995). Preschool Deaf and Hard of Hearing students' interactions during ASL and English storytelling. American Annals of the Deaf, 140(4), 363-370.

Scott, J. A., \& Hoffmeister, R. J. (2017). American Sign Language and academic English: Factors influencing the reading of bilingual secondary school Deaf and Hard of Hearing students. The Journal of Deaf Studies and Deaf Education, 22(1), 59-71. https://doi:10.1093/deafed/enw065

Simms, L., Baker, S., \& Clark, M. D. (2013). The standardized visual communication and sign language checklist for signing children. Sign Language Studies, 14(1), 101-124. doi:10.1353/sls.2013.0029

Skotara, N., Salden, U., Kugow, M., Hanel-Faulhaber, B., \& Roder, B. (2012). The influence of language deprivation in early childhood on L2 processing: An ERP comparison of Deaf native signers and Deaf signers with a delayed language acquisition. BMC Neuroscience, 13. http://www.biomedcentral.com/1471-2202/13/44 
Building Allies and Sharing Best Practices: Cultural Perspectives of Deaf People and ASL Can Benefit All

Snoddon, K. (2015). Using the common European framework of reference for languages to teach sign language to parents of Deaf children. Canadian Modern Language Review, 71(3), 270-287.

Stone, A., Kartheiser, G., Hauser, P. C., Petitto, L. A., \& Allen, T. E. (2015). Fingerspelling as a novel gateway into reading fluency in Deaf bilinguals. PLOS ONE, 10(10).

https://doi:10.1371/journal.pone.0139610

Tevenal, S., \& Villanueva, M. (2009). Are you getting the message? The effects of SimCom on the message received by Deaf, Hard of Hearing, and Hearing students. Sign Language Studies, 9(3), 266-286. www.jstor.org/stable/26190556

Traynor, R. (2016, June 1). The international deaf controversy of 1880. Hearing Health \& Technology Matters. https://hearinghealthmatters.org/hearinginternational/2016/the-internationaldeafness-controversy-of-1880/

Wang, Y.,Trezek, B., Luckner, J. L., \& Paul, P. V. (2008). The role of phonology and phonologically related skills in reading instruction for students who are Deaf or Hard of Hearing. American Annals of the Deaf, 153(4), 396-407. https://doi:10.1353/aad.0.0061

\section{Appendix A}

\section{Recommended Resources for Best Practices}

To learn more about research and professional resources, check out the following:

- The Visual Language and Visual Learning (VL2) research briefs from Gallaudet University are an excellent resource to learn more about ASL and visual strategies:

http://vl2.gallaudet.edu/research/research-briefs/

- The National Association of the Deaf has offered advocacy efforts and materials, including position statements for over 130 years: https://www.nad.org/about-us/position-statements/

- Deaf Education teacher preparation programs offered across the country. For contact information, visit: http://www.deafed.net/Knowledge/PageText.asp?hdnPageld=120.

- The Laurent Clerc National Deaf Education Center offers professional development workshops and resources for educators: http://www3.gallaudet.edu/clerc-center/learning-opportunities/on-site-training.html

These are multimedia materials available for free to teach ASL, early literacy skills and/or include Deaf role models:

- The Bravo Family offer free beginning courses in ASL: https://dcmp.org/series/5-bravo-beginning-asl-videocourse

- ASL nook is a Deaf family modeling storytelling and teaching ASL): www.aslnook.com

- Hands Land includes a series of interactive, researched-based video clips to teach ASL Rhyme and Rhythms, developed by an all Deaf team: www.handsland.com

- Peter's Picture comprises of free interactive, research-tested children's series and app that fosters language, literacy and knowledge of Deaf culture through ASL: https://app.peterspicture.com/

- VL2 Storybook Apps provide stories in ASL and English https://vl2storybookapps.com/

- Signed Stories app provides stories in ASL and English https://www.signedstories.com/apps

To build on the information shared in this article about best practices for teaching and interacting with Deaf children, check out these free resources:

- Best practices for reading with Deaf children: http://www3.gallaudet.edu/clerc-center/learningopportunities/online-learning/fifteen-principles-for-reading-to-deaf-children.html

- These websites provide information on how to create Deaf-friendly space:

- https://www.gallaudet.edu/campus-design-and-planning/deafspace

- http://www.raisingandeducatingdeafchildren.org/2018/04/02/organizing-classrooms-for-deaf-andhard-of-hearing-learners/ 


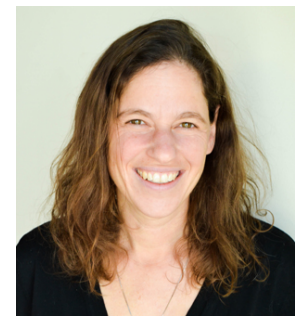

Debbie Golos is an Associate Professor of Deaf Education and Coordinator of the Deaf Education Teacher Preparation Program in the Department of Educational Psychology at the University of Minnesota. She formerly taught 6th grade reading and writing at the California School for the Deaf in Fremont. Her areas of focus for research and teaching are on preventing language deprivation by fostering language, literacy, and identity development for Deaf and Hard of Hearing children through American Sign Language utilizing educational media and literature. She is currently exploring how mindfulness activities in early childhood can promote children's and teachers' well-being.

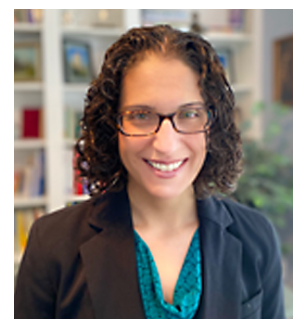

Annie Moses is Director of Periodicals / Editor in Chief at the National Association for the Education of Young Children (NAEYC). She worked at the university level to prepare future early childhood educators for over 15 years. Her research and publications focus on young children's literacy and language development and aspects of early childhood settings that influence their development. This includes investigating the role of media in the lives of developing readers and writers, and another that examines early literacy activities, instruction and assessments utilized in early childhood settings.

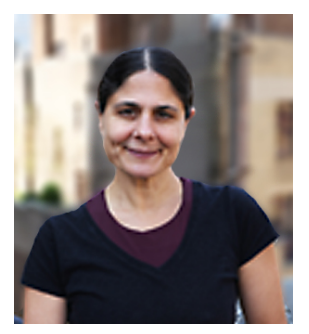

Elaine Gale is an Assistant Professor and Coordinator of the Deaf and Hard of Hearing Teacher Preparation Program at Hunter College, City University of New York (CUNY). She is Chair of the Deaf Leadership International Alliance (DLIA); infusing diverse deaf adults throughout early intervention programs from decision-making to service provision. Her research examines joint attention, theory of mind, and sign language development. Currently, she is co-principal investigator for "Family ASL: Bimodal Bilingual Acquisition by Deaf Children of Hearing Parents" supported by the National Institute on Deafness and other Communication Disorders (NIDCD) of the National Institutes of Health (NIH).

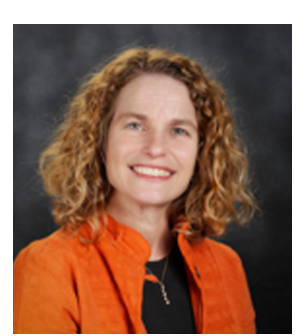

Michele Berke currently works at the California School for the Deaf in Fremont as the Principal for the Early Childhood Education department. Her experience includes directing Gallaudet University's western regional office, coordinating a US Department of Education funded development of an ASL Assessment tool, and teaching college-level Linguistics of ASL courses. She completed her doctoral studies in Speech, Language, and Hearing Sciences from the University of Colorado in Boulder. Her research explored the shared reading practices of Deaf and hearing mothers and their pre-school children. In addition, Michele holds DHH teaching credentials in multiple subjects and is an educational specialist in California. 